\title{
CORRELATION BETWEEN SERUM FERRITIN AND HEART FUNCTION IN CHILDREN WITH MAJOR THALASSEMIA AT DR. SOETOMO HOSPITAL
}

\author{
Evisina Hanafiati Frans, Mahrus A Rahman, Teddy Ontoseno, IDG. Ugrasena
}

Department of Child Health, Faculty of Medicine, Airlangga University/Dr. Soetomo Hospital, Surabaya, Indonesia. E-mail: mahrus_rahman@yahoo.com

\begin{abstract}
Cardiac hemosiderosis in major thalassemia has a high mortality rate. Serum ferritin levels are routinely performed to measure iron deposit in the body. Early detection of cardiac dysfunction by routine echocardiography is very important to prevent complications due to hemosiderosis. A cross-sectional study was performed to analyze the correlation between serum ferritin levels and heart function in thalassemia major children under 18 years old in the Pediatric HematologyOncology Outpatient Clinic at the Dr. Soetomo Hospital, Surabaya. The subjects were children diagnosed with thalassemia major who had received more than ten transfusions and had ferritin levels above $500 \mu \mathrm{g} / \mathrm{L}$. All subjects were selected through consecutive sampling and echocardiography was carried out to measure right ventricular systolic function, left ventricular systolic function, and diastolic function. The analyzed variables were serum ferritin levels, TAPSE index, ejection fraction, and E/A ratio. Data were statistically analyzed using Chi-Square. 82 children were involved as the study subjects that met the inclusion and exclusion criteria, with 1 subject was dropped out due to pneumonia. Serum ferritin was not correlated with right ventricular systolic function, left ventricular systolic function, and diastolic function with Cramer's phi constant 0.14 and $p=0.209$ ); Cramer's phi constant 0.187 and $p=0.09$; and Cramer's phi constant 0.124 and $p=0.264$; respectively. ). Serum ferritin levels in major thalassemia were not correlated with cardiac function
\end{abstract}

Key words: Major thalassemia, serum ferritin, systolic function, diastolic function

\section{INTRODUCTION}

Cardiac hemosiderosis (Iron Overload Cardiomyopathy) in major thalassemia patient has a high mortality rate. ${ }^{1}$ Heart function studies of thalassemia patients with echocardiography concluded that the initial phase of IOC was characterized by an increase of end-systolic volume and borderline ejection fraction, while dilatative cardiomyopathy was found in the later stage. ${ }^{2}$

Serum ferritin has been used for the past few decades to predict iron excess because it is practical and inexpensive. Serum ferritin levels above 1800 $\mu \mathrm{g} / \mathrm{L}$ are associated with cardiac iron levels, and serum ferritin levels above $2500 \mu \mathrm{g} / \mathrm{L}$ are associated with an increased prevalence of cardiac disorders. ${ }^{3}$

Routine echocardiography based on an increase in serum ferritin levels to a certain level is very important to early evaluate the decline in heart function to reduce the mortality due to IOC. Until now, the correlation between serum ferritin and heart function has never been studied at the Regional Hospital Dr. Soetomo Surabaya.

\section{METHODS}

This study was a cross-sectional research involving 82 children of major thalassemia with age under 18 years in the Pediatric Hematology-Oncology Outpatient Clinic at the Dr. Soetomo Hospital Surabaya from July until September 2018. The subjects were children diagnosed with major thalassemia who had received more than ten transfusions and had ferritin levels above $500 \mu \mathrm{g} / \mathrm{L}$. Subjects who suffered from comorbid disorders in the field of hematology such as thalassemia with malignancy, suspected bacterial infections, and congenital heart disease were excluded. All subjects were selected through consecutive sampling and echocardiography was performed to measure right ventricular systolic function, left ventricular systolic function, and diastolic function. The analyzed factors were serum ferritin levels, TAPSE index, ejection fraction, and E/A ratio. Data were statistically analyzed using SPSS ver. 17 and Chi-Square. The study was approved by the Health Research Ethics Committee Dr. Soetomo Hospital, Surabaya with number of 0388/KEPK/VII/2018. 


\section{RESULTS AND DISCUSSION}

A total of 82 children were involved as study subjects that met the inclusion and exclusion criteria, with 1 sample was dropped out due to pneumonia. Based on Table 1, it can be seen that 45 of the 81 subjects $(55.6 \%)$ were female. The average age of patients was 9.75 (95\% CI 8.79-10.71) years. The median weight, mean height, and median upper arm circumference was 25 (minimum-maximum 7-65) kg, 125 (minimum-maximum 68-160) cm, and 20 (minimum-maximum 12-35) $\mathrm{cm}$. Most subjects had good nutritional status (46.9\%), malnutrition (35.8\%), and malnutrition (17.3\%). Hepatomegaly and splenomegaly was found in 45 children $(55.6 \%)$ and 46 children (56.8\%), respectively. The median age for clinical complaints started at the age of 36 months. The majority of study subjects received blood transfusions every 3 weeks with a range of intervals of 2 to 5 weeks (Table 1 ).

The mean serum ferritin level was in the range between $650.0 \mu \mathrm{g} / \mathrm{L}$ and $14,244 \mu \mathrm{g} / \mathrm{L}$ with a median of $2209.06 \mu \mathrm{g} / \mathrm{L}$. Median serum ferritin level in adolescent age group (13-18 years), children age group (7-12 years), preschool age group (4-6 years), and the toddler age group (1-3 years) was 2481.03 $\mu \mathrm{g} / \mathrm{L}(1220-14244 \mu \mathrm{g} / \mathrm{L}), 2179.85 \mu \mathrm{g} / \mathrm{L}(750-10861$ $\mu \mathrm{g} / \mathrm{L}), 2150.64 \mu \mathrm{g} / \mathrm{L}(650-3593 \mu \mathrm{g} / \mathrm{L})$, and 1882.28 $\mu \mathrm{g} / \mathrm{L}(1475-3641.39 \mu \mathrm{g} / \mathrm{L})$, respectively (Table 2).

The results of echocardiography in children with major thalassemia were presented in Table 3. The median value of TAPSE, E/A ratio, and the average
Table 2. Serum ferritin levels in children with major thalassemia

\begin{tabular}{lc}
\hline \multicolumn{1}{c}{ Variables } & $\begin{array}{c}\text { Serum Ferritin Level } \\
\text { (median) ug/L } \\
\text { (minimum-maximum) }\end{array}$ \\
\hline Age group & 2481.03 \\
Adolescent (13-18 years old) & $(1220-14244)$ \\
Children (7-12 years old) & 2179.85 \\
Preschool (4-6 years old) & $(750-10861$ \\
Toddler (1-3 years old) & 2150,64 \\
& $(650-3593)$ \\
Chelating therapy adherence & 1882,28 \\
Poor & $(1475-3641.39)$ \\
Moderate & 2150.64 \\
High & $(1220,51-9000)$ \\
& 2367.03 \\
Transfusion interval & $(750-14244$ \\
Every 2 weeks & 1850,85 \\
Every 3 weeks & $(650-4327.93$ \\
Every 4 weeks & 3200 \\
& \\
& \\
&
\end{tabular}

Table 1. Characteristics of the subjects

\begin{tabular}{lc}
\hline Variables & $\mathbf{n}=\mathbf{8 1}$ \\
\hline Female gender (n;\%) & $45 ; 55.6$ \\
Age (mean; CI 95\%) years old & $9.75 ; 8.79-10.71$ \\
Nutritional status (\%) & \\
$\quad$ Good (n,\%) & $38 ; 46.9$ \\
$\quad$ Moderate malnutrition ( $\mathrm{n}, \%)$ & $29 ; 35.8$ \\
$\quad$ Severe malnutrition (n, $)$ & $14 ; 17.3$ \\
BB (median) kg & $25 ; 7-65$ \\
TB (median) cm & $125 ; 68-160$ \\
LLA (median) cm & $20 ; 12-35$ \\
Hepatosplenomegaly & $46 ; 56,8 \%$ \\
Age at clinical presentation (median) months & $36 ; 1-121$ \\
Age at diagnosis (median) months & $47 ; 2-168$ \\
Transfusion intervals (median) weeks & $3 ; 2-5$ \\
Chelating agent adherence & \\
$\quad$ high (n, \%) & $12 ; 14.8$ \\
$\quad$ moderate $(\mathrm{n}, \%)$ & $56 ; 69.1$ \\
$\quad$ poor (n, \%) & $13 ; 16$ \\
\hline
\end{tabular}


ejection fraction of thalassemia major children was $2.19 \mathrm{~cm}(1.2-4.34), 1.89(0.52-2.75)$, and $71.48 \%$ (69.55). - 73.41), respectively.

Table 4 showed heart function in each group of serum ferritin levels. In this study, there were 41 patients (50.6\%) with abnormal TAPSE values and 40 patients (49.4\%) with normal TAPSE values. There were 14 patients (17.2\%) with diastolic dysfunction and 67 patients $(63.8 \%)$ with a normal diastolic function. There were 2 patients $(2.5 \%)$ with left ventricular systolic dysfunction values below the normal ejection fraction of $51.21 \%$ and $44.55 \%$.

In major thalassemia children with serum ferritin levels $\geq 2500 \mu \mathrm{g} / \mathrm{L}$, there were 20 of 34 children (58.8\%) with an abnormal TAPSE index, whereas in major thalassemia children with serum ferritin levels $<2500 \mu \mathrm{g} / \mathrm{L}$, there were 21 of 47 children (44.7\%) with abnormal TAPSE index. Levels of ferritin in the serum of major thalassemia children were not correlated to right ventricular systolic function (Cramer's phi constant 0.14 at $p=0.209$ ).

There were 2 children with an abnormal ejection fraction and ferritin levels $\geq 2500 \mu \mathrm{g} / \mathrm{L}$. The results of the Chi-Square test showed no significant correlation between serum ferritin levels and left heart systolic function (Cramer's phi constant 0.187, $p=0.09$ ).

In major thalassemia children with serum ferritin levels $>2500 \mu \mathrm{g} / \mathrm{L}$, there were 4 of 34 children (11.8\%) with an abnormal E/A ratio. Meanwhile, in major thalassemia children with serum ferritin levels

Table 3. Cardiac function of children with major thalassemia

\begin{tabular}{lc}
\hline \multicolumn{1}{c}{ Variables } & Value \\
\hline TAPSE (median, min-max) cm & $2.19(1.2-4.34)$ \\
E/A ratio (median, min-max) & $1.89(0.52-2.75)$ \\
$\begin{array}{l}\text { Ejection fraction } \\
\text { (mean, 95\% CI) \% }\end{array}$ & $71.48(69.55-73.41)$ \\
\hline
\end{tabular}

$<2500 \mu \mathrm{g} / \mathrm{L}$, there were 10 out of 47 children $(21.3 \%)$ the abnormal E/A ratio. Serum ferritin levels in children with major thalassemia were not correlated to diastolic function (Cramer's phi constant 0.124 and $p=0.264$ ).

This study was a cross-sectional study which aimed to determine the correlation between serum ferritin levels and heart function in major thalassemia children in the Dr. Soetomo Hospital. Non-transferrin-bound iron will enter specific cells, especially hepatocytes, cardiomyocytes, anterior pituitary cells, and pancreatic cells (alpha cells). Iron accumulation within cells will stimulate formation of reactive-oxygen species, which damage lipids, proteins, Deoxyribose Nucleic Acid (DNA), and subcellular organelles, including lysosomes and mitochondria. This damage will result in cellular dysfunction, apoptosis, and necrosis leading to organ toxicity and organ dysfunction. ${ }^{4}$

In clinical practice, serum ferritin has been commonly used to assess the severity of iron overload and the effectiveness of therapy. The benefits of serum ferritin are its wide availability, inexpensive cost, and positive correlation with patient morbidity and mortality. However, the measurement of serum ferritin is completely reliable because it can be affected by inflammation, liver disease, and malignancy. Echocardiographic-based studies showed that a good prognosis was obtained if serum ferritin was $<2500 \mu \mathrm{g} / \mathrm{L}^{5}$

The subjects of this study were children aged up to 18 years most of them were 9 years old. In this study, the majority of major thalassemia children were diagnosed at the age of 46 months (4 years) with the youngest age and the oldest age was diagnosed at the age of 2 months and 168 months (14 years), respectively. Most of the clinical complaints was observed at the age of 36 months with the youngest age ofcomplaint was 1 month.

Table 4. Correlation between serum ferritin and cardiac function

\begin{tabular}{ccccc}
\hline Variables & $\begin{array}{c}\text { Ferritin } \mathbf{2 5 0 0} \mathbf{\text { ug}} / \mathbf{L} \\
(\mathbf{n}=\mathbf{3 4})\end{array}$ & $\begin{array}{c}\text { Ferritin }<\mathbf{2 5 0 0} \mathbf{u g} / \mathbf{L} \\
\mathbf{( n = 4 7 )}\end{array}$ & $\mathbf{p}$ & $\mathbf{r}$ \\
\hline TAPSE & 20 & 14 & 0.209 & $0.140^{\star}$ \\
Abnormal & 14 & 26 & & \\
Normal & & & & \\
Ratio E/A & 4 & 10 & 0.264 & 0.124 \\
Abnormal & 30 & 37 & & \\
Normal & 2 & 0 & 0.09 & 0.187 \\
Ejection fraction & 32 & 47 & & \\
Abnormal & & & &
\end{tabular}

* Chi-Square, significant at $p<0.05$ 
These results were comparable with research conducted by Indonesian Thalassemia Foundation in Banyumas which reported mean age of 12.3 years with a mean age at initial diagnosis of thalassemia was 3.7 years and the earliest was at age of 2 months. $^{6}$

In this study, there were 46 children (56.8\%) with hepatosplenomegaly. This result was in accordance with the latest Thalassemia International Federation (TIF) in 2014 suggesting that complaints of major thalassemia including parlor, mild jaundice and hepatosplenomegaly began to appear clinically at the age of 6 to 24 months, which are?

Based on gender, the number of male patients was 22 ( $45.8 \%$ ). Study by Bornaun found that 35\% of thalassemia children were male. ${ }^{8}$ Whereas, while this study was somewhat different from Ibrahim in Egypt that found $70 \%$ of thalassemia children were male. ${ }^{9}$ Thalassemia is a genetic disease caused by an autosomal recessive single allele factor called chromosome 11p15,5. However, it is not genetic diseases caused by allele factors linked to sex/sex chromosomes. ${ }^{5}$ Nutritional status on the subject study was assessed using upper arm circumference. Based on nutritional status, most subjects had good nutrition ( $46.9 \%$ ) moderate malnutrition (35.8\%), and severe malnutrition (17.3\%). Nutritional deficiencies commonly found in thalassemia were due to hemolytic anemia, increased nutritional requirements, and another morbidity such as iron overload diabetes, and use of iron chelation. ${ }^{10}$

The majority of patients had moderate levels of adherence to iron chelation therapy (69.1\%), with $16 \%$ of patients and $14.8 \%$ of patients had a low level of adherence and a high level of adherence, respectively. The results of a study in India involving 91 major thalassemia children reported that the majority of patients had moderate adherence (48.4\%), low level of adherence (41.9\%), and a high level of adherence (7.5\%). The instrument used in the two studies was the same, namely the Morisky Medical Adherence Scale-8 (MMAS-8) questionnaire. $^{11}$

Serum ferritin is a simple, non-invasive, widely available, and more economical laboratory parameters that are used by researchers use it to measure serum ferritin levels to determine iron status in the body. Serum ferritin is also associated with body iron levels. ${ }^{12}$ Research in Europe proved a positive correlation between serum ferritin levels and iron concentration in the liver $(r=0.63) .{ }^{13}$

Serum ferritin levels above $2500 \mu \mathrm{g} / \mathrm{L}$ are associated with an increased risk of heart and endocrine disease and are a signal to optimize the dose of chelation therapy. Single measurement levels of serum ferritin can lead to misinterpretations or may not represent the condition of the patient, due to the high variability, especially if the patient is experiencing inflammation, infections, vitamin C deficiency, liver dysfunction, and iron overload (levels above $4000 \mu \mathrm{g} / \mathrm{L}$ ). This implies the need to evaluate cardiac siderosis as early as possible. ${ }^{14}$

In this study, there were 36 patients ( $44.4 \%$ ) with right ventricular systolic dysfunction and 14 patients (17.2\%) with diastolic dysfunction. There were 2 patients (2.5\%) with left ventricular systolic dysfunction with an ejection fraction below normal levels of $51.21 \%$ and $44.55 \%$, respectively.

The results of this study was comparable with case-control design studies to assess right heart function in 85 major thalassemia children in Turkey with a mean TAPSE value of $2.1 \pm 0.3 \mathrm{~cm}$ and $\mathrm{E} / \mathrm{A}$ ratio $1.4 \pm 0.2$. Right ventricular diastolic dysfunction in major thalassemia occurs before no systolic use. ${ }^{8}$

The results of this study was different from the study of 100 thalassemia major children and 100 controls aged up to 18 years in Egypt and Saudi Arabia that reported left and right ventricular dysfunction measured by tissue doppler echocardiography, although the results of conventional echocardiography showed normal heart function. In the study, the TAPSE value of $2.41 \pm 0.42$ and E/A ratio of $2.2 \pm 0.8$ were found. ${ }^{9}$

This study showed that serum ferritin level of major thalassemia was not correlated with right ventricular systolic function (Cramer's phi constant $0.14, p=0.29$ ). The results of the Chi-Square test showed no significant correlation between serum ferritin levels and left ventricular systolic function (Cramer's phi constant 0.187, $p=0.09$ ). Serum ferritin levels in the thalassemia major children were not correlated with diastolic function (Cramer's phi constant 0.124 at $p 0.264$ ).

A case-control study in Turkey involving 63 major thalassemia patients and controls aged 4 to 21 years reported a low E/A ratio in major B-thalassemia patients compared with controls, but there was no significant correlation between serum ferritin with diastolic heart function. ${ }^{15}$ Research by Sayed in Egypt in 56 patients aged 6-16 years with thalassemia major reported no correlation between serum ferritin levels and ejection fraction $(p=0.13)$, but there was a significant correlation between the ratio of $E / A$ and ferritin levels $(p=0.00) .{ }^{16}$

A prospective study of 30 major thalassemia children in Bangalore, India reported a significant correlation between serum ferritin levels and ejection fraction $(r=-0.051$ at $p<0.001)$ and insignifant correlation between the E/A ratio and serum ferritin $(r=-0.187) .{ }^{17}$ Eghbali in Iran proved a 
significant correlation between serum ferritin levels and ejection fraction $(r=0.3, p=0.05)$ in 66 thalassemia children aged 3-26 years with an average age of $16 \pm 9$ years. Ferritin levels ranged from 303-8333 $\mu \mathrm{g} / \mathrm{L}$, with mean serum ferritin of $1912 \pm 1748 \mu \mathrm{g} / \mathrm{L}{ }^{18}$ Research in Egypt reported that serum ferritin levels was not correlated with the E/A ratio (correlation coefficient 0.12 , p. 48 ), but serum ferritin levels were correlated with the parameters of mitral inflow diastolic wave and isometric contraction time. ${ }^{19}$

Research on thalassemia patients aged 14-29 years using echocardiographic modality and MRI T2 * showed correlation between serum ferritin and heart $\mathrm{T} 2$ * ( $\mathrm{s} \mathrm{s}=-0.329, \mathrm{P}=0.002)$, but no correlation between serum ferritin and ejection fraction $(p=0.399)$. This study concluded that serum ferritin levels could be used for the diagnosis of iron overload in areas with unavailability of MRIT $2 *{ }^{20}$

The abnormal TAPSE index in the subject of this study and the low value of the ejection faction indicated that there was a systolic function in major thalassemia patients. Unfortunately, there was no baseline data on the initial heart function parameters at the start of the diagnosis of thalassemia major.

The impaired cardiac function was due to the increased susceptibility of the right ventricle to the effects of iron deposition because of the thin walls. ${ }^{21}$ An increased E/A ratio in patients with thalassemia was a sign of diastolic dysfunction. Iron myocardium deposition in some major thalassemia patients does not directly affect left ventricular contractility, but causes left ventricular restriction and was detected as diastolic (restrictive) dysfunction. An increased E/A ratio represents an increase in the preload phase due to chronic anemia. ${ }^{22}$

Study by Kremastinos aboutthe comparison of serum ferritin between major thalassemia patients and clinical heart failure showed significant differences between serum ferritin of thalassemia major patients with clinical right and left heart failure. Serum ferritin used in the study was taken from an average of 30 measurements of serum ferritin over the past five years. The serum ferritin levels were considered more accurate to be an iron reserve index due to general fluctuation of serum ferritin. ${ }^{23}$

The limitations of this study were the use of heart function parameters only restricted to TAPSE, ejection fraction, and E/A ratio. The researchers did not measure the parameter of other functions using doppler echocardiography. In addition, there was no baseline data on the initial heart function parameters at the start of the diagnosis. Ferritin levels in this study were the average ferritin levels within the last three months because researchers did not obtain data on ferritin levels longer than three months due to routine ferritin levels measurement on patientsevery three months. However, researchers did not us standart modalities in measuring cardiac hemosiderosis, MRI T2 ${ }^{*}$, due to its limited availability.

\section{CONCLUSION AND SUGGESTION}

There was no correlation between serum ferritin levels and systolic and diastolic heart function in thalassemia major children. Researchers suggested the measurement of cardiac function parameters with conventional echocardiography and tissue Doppler echocardiography periodically at the beginning of the diagnosis. Further study with the MRI T2 * modality was needed to examine cardiac hemosiderosis in children with major thalassemia.

\section{REFERENCES}

1. Koonrungsesomboon N, Chattipakorn SC, Fucharoen $\mathrm{S}$, Chattipakorn N. Early detection of cardiac involvement in thalassemia: From bench to bedside perspective. World J Cardiol, 2013; 5(8): 270-9.

2. Maggio A, Filosa A, Vitrano A, Aloj G, Antonis Kattamis, Adriana Ceci, et al. Iron-chelation therapy in thalassemia major: A systematic review with meta-analyses of 1520 patients included on randomized clinical trials. Blood Cells Mol Dis, 2011; 47: 166-75.

3. Yaman A, Isik P, Yarali N, Karademir S, Cetinkaya S, Bay $A$, et al. Common complications in beta-thalasemia patients. Int J Hematol Onc, 2013; 23: 193-9.

4. Taher AT, Weatherall DJ, Cappelini MD. Thalassemia. Lancet, 2018; 391: 155-67.

5. Rund D, Rachmilewitz E. Beta-thalasemia. N Engl J Med, 2005; 353: 1135-46.

6. Rejeki DSS, Nurhayati N, Supriyanto, Kartikasari E. Studi epidemiologi deskriptif talasemia. Jurnal Kesehatan Masyarakat Nasional, 2012; 7: 139-44.

7. Viprakasit V, Origa R. Genetic basis, patofisiologi and diagnosis. In: Cappellini, Cohen A, Porter J, Taher A, Viprakasit $V_{1}$ (eds). Guidelines for the management of transfusion dependent thalasemia. 3 Ed., Nicosia, Thalasemia International Federation, 2014; 14-27.

8. Bornaun H, Dedeoglu R, Oztarhan, Dedeoglu S, Erfidan $\mathrm{E}$, Gundogdu $\mathrm{M}$, et al. Detection of early right ventricular dysfunction in young patients with thalassemia major using tissue Doppler imaging. Iran J Pediatr, 2016; 26: 1-10.

9. Ibrahim MH, Azab AA, Kamal NM, Salama MA, Ebrahim SA, Shahin AM, et al. Early detection of myocardial dysfunction in poorly treated pediatric thalassemia children and adolescents: Two study centers experience. Ann Med Surg, 2016; 9: 6-11.

10. Vichinsky E, Levine L, Bhatia S, Bojanowski J, Coates T, Foote $D$, et al. Standards of care guidelines for 
thalasemia children. Children's Hospital \& Research Center Oakland, 2012; 1-28.

11. Panda K, Mishra NR, SK Jena. Adherence to deferasirox among beta-thalassemia major children a cross-sectional study in a tertiary care hospital. Indian J Child Health, 2017; 5(1): 38-41.

12. Olivieri NF, Brittenham GM. Iron-chelating therapy and the treatment of thalassemia. Blood, 1997; 89(3): 739-61.

13. Cappelini MD, Cohen A, Piga A, Bejaoui M, Perrotta S, Agaoglu $L$, et el. A phase-3 study of deferasirox (ICL670), a once-daily oral iron chelator, in patients with $\beta$ thalassemia. Blood, 2006; 107: 3455-3462.

14. Porter JB, Walter PB, Neumayr LD, Evans P, Bansal S, Garbowski $M$, et al. Mechanisms of plasma nontransferrin bound iron generation: Insights from comparing transfused diamond blackfin anemia with sickle cell and thalassemia patients. $\mathrm{Br} J$ Haematol, 2014; 167(5): 692-6.

15. Yaprak I, Aksit S, Ozturk C, Bakiler AR, Dorak C, Turker $M$. Left ventricular diastolic abnormalities in children with beta-thalassemia major: A Doppler echocardiographic study. Turk J Pediatr, 1998; 40(2): 201-9.

16. Sayed SZ, Aly BA, Hakim A, Omar SM, Amin AS. The early cardiac involvement in patients with betathalassemia major. The Egyptian Heart Journal, 2013;65, 243-9.

17. Shivanna NJ, Ramachamdrappa RM, Ambica, Munirathnam G. Cardiac abnormalities in children with thalassemia major: Correlation of echocardiographic parameters with serum ferritin levels. Int J Contemp Pediatr, 2016; 3(1):12-5.

18. Eghbali A, Taherahmadi H, Bagheri B, Nikanjam S, Ebrahimi LM. Association between serum ferritin level and diastolic cardiac function in patients with major $\beta$-thalassemia. Iran J Ped Hematol Onc, 2015; 2: 83-6.

19. Ragab AM, Fathy WM, El - Aziz WF, Helal RT. The diagnostic value of pulsed wave tissue Doppler imaging in asymptomatic beta-thalassemia major children and young adults: Relation to chemical biomarkers of left ventricular function and iron overload. Mediterr J Hematol Infect Dis, 2015; 7(1): 1-11.

20. Majd Z, Haghpanah S, Ajami GH, Matin S, Namazi H, Bardestani $M$, et al. Serum ferritin levels correlation with heart and liver MRI and LIC in patients with transfusion-dependent thalassemia. Iran Red Crescent Med J, 2015; 17(4): 1-5.

21. Pennell DJ, Udelson JE, Arai AE, Bozkurt B, Cohen AR, Galanello $R$, et al. Cardiovascular function and treatment in $\beta$-thalassemia major: A consensus statement from the American Heart Association. Circulation, 2013; 128: 281-308.

22. Garadah TS, Kassab S, Mahdi N, Taleb AA, Jamsheer A. Pulsed and tissue Doppler echocardiographic changes in patients with thalassemia major. Clinical Medicine Insights: Blood Disorders, 2010; 3: 1-8.

23. Kremastinos DT, Tsetsos GA, Tsiapras DP, Karavolias GK, Ladis VA, Kattamis CA. Heart failure in betathalassemia: 5 years follow up study. Am J Med, 2001; 111: 349-54. 